\title{
Heat transfer characteristics of a two-phase closed thermosyphon considering the working fluid filling ratio
}

\author{
S. H. Oh, S. I. Kim, J. W. Choi, K. J. Lee \& W. P. Chun \\ Korea Institute of Energy Research, Korea
}

\begin{abstract}
In this study, the heat transfer performance of a two-phase closed thermosyphon was experimentally measured and compared according to the working fluid filling ratio. The total length of the thermosyphon was $1,000 \mathrm{~mm}$ and the lengths of the evaporator and condenser were varied to 5:5, while the working fluid was filled to $20 \%, 40 \%, 60 \%$, and $80 \%$ for the experiments. The working fluid was HFE 7100 . The evaporation region temperature is $90^{\circ} \mathrm{C}$ and to exchange heat energy, the condensation region was supplied air. To achieve high heat transfer performance, the condensation region of thermosyphon had annular round fins. The air flow velocity of condensation region was $2 \mathrm{~m} / \mathrm{s}$. This study's result was presented as a value of heat transfer amount and effective thermal conductivity. The heat transfer amount of thermosyphon was measured at condensation region. The effective thermal conductivity was calculated using themosyphon's temperature at evaporation and condensation region. The highest heat transfer performance for the thermosyphon and effective thermal conductivity were obtained with a filling ratio of $40 \%$. And it means that the optimal value of working fluid filling ratio exists.
\end{abstract}

Keywords: thermosyphon, heat transfer, working fluid ratio, effective thermal conductivity.

\section{Introduction}

Thermosyphon is widely used by heat exchanger, electronic device cooling and various energy conversion systems, because it is economical, operates at low temperatures, and has high heat transfer performance. In general, the effective conductivity of the thermosyphon can be a maximum of 500 times that of copper 
[1]. There are no flow channels inside the thermosyphon, but rather, circulation is driven by gravity as the working fluid changes phases. Thus, the performance of the thermosyphon varies depending on the working fluid material, ratio and thermosyphon shape.

Many studies have been carried out about thermosyphon. And the objective of research can be defined based on the type of working fluid and shape, etc. Park and Lee [2] carried out an experimental study on the performance of vertical twophase closed thermosyphon with three working fluid mixture. Shiraishi et al. [3] performed the experimental test about a thermosyphon's critical heat transfer rate at various conditions such as aspect ratio, filling ratio, working fluid property and pressure.

Research to effort the correlations among the factors affecting performance have been widely investigated. Xin et al. [4] and Imura et al. [5] were introduced about the correlation about heat transfer coefficient of the evaporator section. Recently, Terdtoon et al. [6, 7] and Payakaruk et al. [8] carried out studies on the relationship between various dimensionless parameters and the heat transfer performance of the thermosyphon.

Although research like this has been conducted on the thermosyphon for a long time, experimental studies are needed to investigate the new developed working fluid due to environmental issue. In addition, experimental research is ongoing critical problems that still need to be tackled on the thermosyphon shape for various applications.

From this perspective, the objective of this study was to perform experimental research and analysis of heat transfer characteristics about working fluid ratios, using HFE 7100.

\section{Experimental setup}

Fig. 1 shows the schematic diagram of the experimental facility. In order to conduct the experimental test about thermosyphon, the evaporator of the thermosyphon was heated using hot water. Air flowed through the condenser for heat exchange and the temperature of the air at the inlet and outlet were measured. Water temperatures of $90^{\circ} \mathrm{C}$ were used in the experiment to heat the evaporator and the heated water was continuously circulated for uniform temperature maintenance. The dimensions of the thermosyphon are shown in Fig. 2 in detail. For the heat transfer, an annular fin was installed for the condenser of the thermosyphon. The total length was $1,000 \mathrm{~mm}$ and the lengths of the condenser and evaporator were the same for all the thermosyphons. The ratio of the evaporator to condenser length was 5:5 and adiabatic region is contained evaporator region, respectively. The heat exchange duct corresponding to the condenser of Fig. 1 was fabricated in the same size as the thermosyphon condenser for the experiments. The duct was a rectangular shape. The air flow rate into the condenser was $2 \mathrm{~m} / \mathrm{s}$ in the cross sectional area of the duct where the condenser was installed. Cross sectional areas of the ducts where the thermosyphons was $0.03 \mathrm{~m}^{2}$. 
The thermosyphon was manufactured in aluminum. HFE 7100 was used as the refrigerant. Table 1 shows the detailed specifications of the HFE 7100. In this study, in order to analysis the heat transfer characteristics of the thermosyphon according to the working fluid filling ratio, the filling ratio was varied to be $20 \%$, $40 \%, 60 \%$, and $80 \%$ for the experiment. The filling ratio was based on the evaporator volume. The numbered positions marked in Fig. 2 are the locations where the temperature was measured for the thermosyphon. The temperatures were measured by attaching TCs to the external surface of the thermosyphon and real-time measurement was carried out. The experiment was conducted in a steady state and a temperature deviation of approximately $\pm 1^{\circ} \mathrm{C}$ was maintained during measurement. Also, circular round fins were manufactured for the condenser to enhance the heat exchange, and its detailed dimensions are shown in Figs 1 and 2.

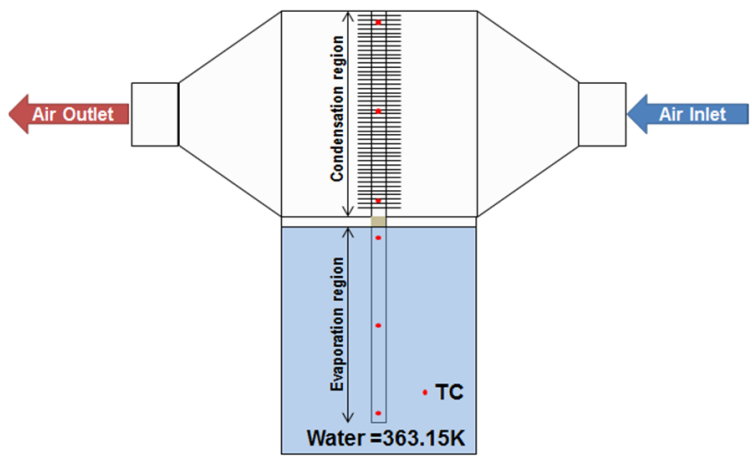

Figure 1: Schematic of test facility.

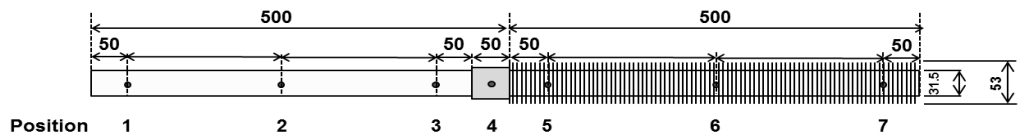

Figure 2: Schematic of thermosiphon.

Table 1: The properties of HFE 7100.

\begin{tabular}{|c|c|}
\hline Boiling point $\left[{ }^{\circ} \mathrm{C}\right]$ & 61 \\
\hline Pour point $\left[{ }^{\circ} \mathrm{C}\right]$ & -135 \\
\hline Density $\left[\mathrm{kg} / \mathrm{m}^{3}\right]$ & 1520 \\
\hline Viscosity $[\mathrm{cSt}]$ & 0.38 \\
\hline Specific heat $[\mathrm{J} / \mathrm{kg} / \mathrm{K}]$ & 1172 \\
\hline Thermal conductivity $[\mathrm{W} / \mathrm{m} / \mathrm{K}]$ & 0.069 \\
\hline Surface tension $[\mathrm{mN} / \mathrm{m}]$ & 13.6 \\
\hline Heat of vaporization $[\mathrm{kJ} / \mathrm{kg}]$ & 125.6 \\
\hline
\end{tabular}




\section{Result}

The experimental results are expressed with respect to total heat transfer rate (Q) and effective thermal conductivity $\left(\mathrm{k}_{\mathrm{eff}}\right)$. In this study, the heat transfer into the evaporator section of the thermosyphon by the hot water tank at a constant temperature is denoted by $\mathrm{Q}_{\text {in }}$ while heat release to the air passing through the duct in the condenser section is denoted by $\mathrm{Q}_{\text {out }}$, and thereby both of them was assumed equal since heat loss which may occur was minimized by means of insulating the experimental facility. Accordingly, only $Q_{\text {out }}$ was calculated by measuring the air temperature difference between the inlet and outlet of the duct by the following Eq. (1). Considering that the temperature difference between the inlet and outlet air in the evaporator section was measured by $15-20^{\circ} \mathrm{C}$, we reasonably employed the specific heat property with the averaged value of both temperatures.

$$
Q_{\text {out }}=\dot{m} c_{p}\left(T_{\text {air out }}-T_{\text {air in }}\right)
$$

The effective thermal conductivity is one of important parameter to evaluate the thermosyphon's heat transfer performance. To calculate the effective thermal conductivity, the evaporator and condenser temperature was needed. Therefore, for the evaporator and condenser, the averages of 3 temperature measurement locations each were used while only one temperature measurement location was used in the insulator.

\subsection{Total heat transfer rate}

The total heat transfer rate for experimental case is shown in Fig 3. Total heat transfer rate is about $0.7-1 \mathrm{~kW}$. As well known, the filling ratio is one of the effective parameter in thermosyphon. At filling ratio $40 \%$, it had a maximum total heat transfer rate. As filling ratio was decreased from $100 \%$ to $40 \%$, the total heat transfer rate was increased. However, the total heat transfer rate was rapidly decreased at filling ratio $20 \%$. This is due to thick layer film of working fluid. As working fluid mass increased, the heat transfer performance was increased. However, higher filling ratio of working fluid made thick film boiling layer, and large working fluid bubbles. These phenomena had direct effect on heat transfer performance of thermosyphon and can decrease the thermosyphon's heat transfer performance. And it also means that the optimal value of filling ratio was existed. In this study, we only performed 4 cases of filling ratio. Therefore, $40 \%$ was not correct optimal value. However, the optimal value can be predicted between $20 \%$ and $40 \%$ of filling ratio.

\subsection{Effective thermal conductivity}

The effective thermal conductivity is defined by Eq. (2). And the result of effective thermal conductivity is shown in Fig. 4. The effective thermal conductivity value was about from 12,000 to $50,000 \mathrm{~W} / \mathrm{mK}$. It showed that the thermosyphon using HFE 7100 was useful heat transfer device. The tendency of effective thermal 


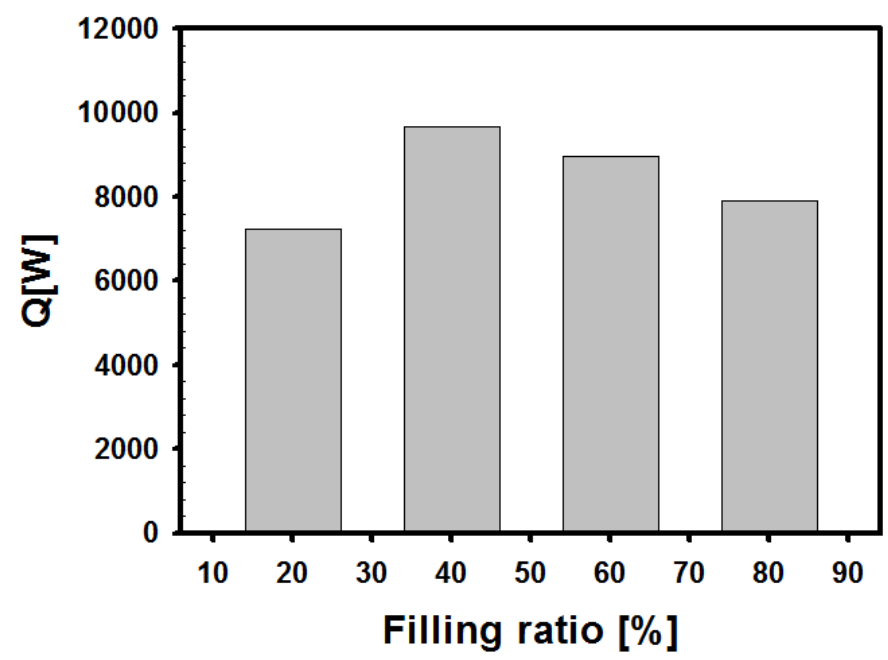

Figure 3: Graph of total heat transfer rate vs. filling ratio.

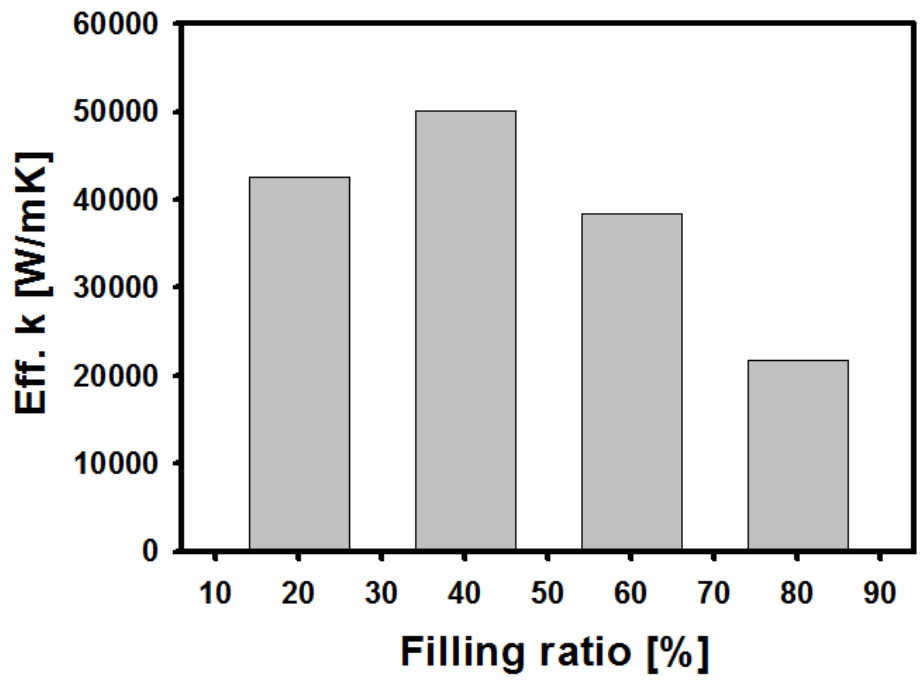

Figure 4: Graph of effectiveness thermal conductivity vs. filling ratio.

conductivity was similar to total heat transfer rate result. However, at $20 \%, 60 \%$ of filling ratio cases, the result was little different. At total heat transfer rate result, filling ratio $60 \%$ heat transfer rate was higher than filling ratio $20 \%$. However, at effective thermal conductivity result, filling ratio $20 \%$ effective thermal 
conductivity value was higher than filling ratio $60 \%$. Although the total heat transfer rate is higher, the effective thermal conductivity is smaller due to working fluid boiling condition at each filling ratio. It means that at $20 \%$ filling ratio thermosyphon's heat transfer performance is better than $60 \%, 80 \%$. And we can be also predicted that the optimal value of filling ratio will be positioned between $20 \%$ and $40 \%$.

$$
k_{e f f}=Q \cdot l / A_{c}\left(T_{e v p}-T_{c o n}\right)
$$

\section{Conclusion}

In this study, the heat transfer performance of a two phase single thermosyphon was measured for various working fluid ratios. For refrigerant, HFE 7100 was used. The following conclusions were obtained through this study.

1. The thermosyphon using HFE 7100 had a high value effective thermal conductivity.

2. In this study, the highest heat transfer performance was obtained for the working fluid filling ratio of $40 \%$.

3. The total heat transfer tended to increase as the working fluid ratio decreased from $80 \%$ to $40 \%$. However, at $20 \%$ filling ratio, total heat transfer rate is rapidly decreasing due to opposite effect of higher height working fluid. It means that the optimal filling ratio value existed between filling ratio $20 \%$ and $40 \%$.

\section{Acknowledgement}

This work was conducted under framework of the research and development program of the Korea Institute of Energy Research (B6-2406).

\section{References}

[1] Dunn, P.D. \& Reay, D.A., Heat pipes, Third Ed. Pergamon Press, Oxford, U.K, 1994.

[2] Park, R. \& Lee, Y., Two-phase closed thermosyphons with two fluid mixture. Proc. of the $8^{\text {th }}$ Int. Heat Pipe Conf., Beijing, China, vol 2. pp. 220-225, 1992.

[3] Shiraishi, P., Terdtoon, P. \& Murakami, M, Correlations to predict heat transfer characteristics and condensation of a thermosyphone. Proc. of the $5^{\text {th }}$ Int. Heat Pipe Symposium., Melbourne, Australia, 1996.

[4] Xin, M.D., Chen, G. \& Chen, Y.G., Flow and heat transfer in two-phase closed thermosyphon. Proc. of the $6^{\text {th }}$ Int. Heat Pipe Conf., 1987.

[5] Imura, H., Kusada, H., Oyata, J., Miyazaki, T. \& Sakamoto, N., Heat transfer in two-phase closed-type thermosyphons, Transactions of Japan Society of Mechanical Engineers 22, pp. 485-493, 1977. 
[6] Terdtoon, P., Waowaew, N. \& Tantakom, P., Internal flow patterns of an inclined, closed two-phase thermosyphon at critical state: case study 1, effect of aspect ratio, Experimental Heat Transfer, pp. 347-358, 1999.

[7] Terdtoon, P., Waowaew, N. \& Tantakom, P., Internal flow patterns of an inclined, closed two-phase thermosyphon at critical state: case study 1, effect of Bond number, Experimental Heat Transfer, pp. 359-373, 1999.

[8] Payakaruk, T., Terdtoon, P. and Ritthidecj, S., Correlations to predict heat transfer characteristics of an inclined closed tow-phase thermosyphon at normal operating conditions, Applied Thermal Engineering, 20, pp. 781-790, 2000 . 